\title{
Implementation of small-group reflection rounds at an emergency medicine residency program
}

\author{
Leana S. Wen, MD, MSc** Justin T. Baca, MD, PhD*; Patricia O’Malley, MD; Kriti Bhatia, MD; \\ David Peak, MD'; J. Kimo Takayesu, MD, MSc ${ }^{\dagger}$
}

\begin{abstract}
Few residency curricular interventions have focused on improving well-being and promoting humanism. We describe the implementation of a novel curriculum based on smallgroup reflection rounds-the Emergency Medicine Reflection Rounds (EMRR) - at a 4-year US emergency medicine (EM) residency. During the inaugural year (2010-2011), nine residents volunteered to take part in 1-hour monthly sessions with faculty facilitators. Residents were provided with a confidential environment to discuss difficult ethical and interpersonal encounters from their clinical experiences. Ongoing feedback from participants was solicited, culminating with a four-question survey in which all respondents remarked that the EMRR contributed to improving their own well-being and agreed that it provided an important forum for residents to discuss difficult issues in a safe environment. In this article, we describe our innovation as an example of a wellness initiative that has promoted reflective practice and fostered cooperative learning around the communication, professional, and ethical challenges inherent in EM practice. Our EMRR model may be useful to other EM residences looking to supplement their wellness curriculum.
\end{abstract}

\section{RÉSUMÉ}

Les programmes de résidence comprennent peu d'interventions portant sur l'amélioration du bien-être et la promotion du sentiment d'humanité. Nous décrivons ici la mise en $œ u v r e$ d'une initiative novatrice, consistant en des séances de réflexion en petits groupes-appelées séances de réflexion en médecine d'urgence (SRMU)—offerte dans un programme de résidence en médecine d'urgence (MU), d'une durée de 4 ans, aux États-Unis. Au cours de la première année d'existence (2010-2011), neuf résidents ont accepté de participer à des séances mensuelles, d'une durée de 1 heure, dirigées par des animateurs membres de la faculté. Les résidents étaient placés dans un environnement confidentiel, ce qui leur permettait de discuter de difficultés d'ordre éthique et interpersonnel, tirées de leur expérience clinique. On demandait aux participants de faire de la rétroaction continue, et celle-ci a atteint son point culminant dans une enquête qui comptait quatre questions, dans laquelle tous les répondants ont souligné que les SRMU avaient contribué à I'amélioration de leur propre bien-être, et ils étaient d'accord pour dire que celles-ci avaient constitué un lieu d'échanges importants, qui leur avait permis de discuter de questions difficiles dans un environnement sûr. Nous présentons, dans l'article, notre expérience novatrice comme un exemple d'initiative de promotion du bien-être, qui a favorisé la pratique réflexive et l'apprentissage coopératif, relativement à des difficultés d'ordre professionnel et éthique et à des problèmes de communication, inhérents à la pratique de la MU. Notre modèle de SRMU peut se montrer utile dans d'autres programmes de résidence en MU dont les responsables aimeraient enrichir le contenu en matière de bien-être.

Keywords: burnout, humanism, reflection, residency training

The prevalence of depression increases during internship and residency, with accompanying increases in cynicism and burnout and a decrease in humanistic orientation. ${ }^{1}$ Studies have shown that students and residents are reluctant to seek help, attributed largely to the "silent bravado" and "hidden curriculum" of medical culture. ${ }^{2}$

Few interventions have focused on concrete ways to improve emotional well-being during medical training.

From the *Harvard Affiliated Emergency Medicine Residency, Division of Emergency Medicine, Brigham \& Women's Hospitals/Massachusetts General Hospital; †Department of Emergency Medicine, Massachusetts General Hospital; and łDepartment of Emergency Medicine, Brigham \& Women's Hospital, Boston, MA.

Presented as part of the Innovations in Emergency Medicine exhibit at the 2012 Society for Academic Emergency Medicine Meeting, Chicago, IL, May 2012.

Correspondence to: Dr. Leana S. Wen, Harvard Affiliated Emergency Medicine Residency, Brigham \& Women's Hospitals/Massachusetts General Hospital, 178 Marlborough Street, \#5, Boston, MA 02116; Wen.Leana@gmail.com.

This article has been peer reviewed. 
Peer discussion groups at a medical school emphasized to participants that their struggles were not unique; such reflective practice interventions have been viewed positively by medical students. ${ }^{3}$ To our knowledge, the pilot efforts at the medical school level have not been replicated in emergency medicine (EM) residency training, yet educational curricula directed at combating the incidence of burnout during the demanding course of EM residency are critically needed.

\section{RATIONALE}

Our 4-year US EM program has developed a novel curricular intervention to address the need for improving well-being and promoting humanism: the Emergency Medicine Reflection Rounds (EMRR). This article describes the implementation and initial evaluation of this pilot project.

\section{DESCRIPTION OF THE INNOVATION}

In 2010, a second-year resident interested in the topic of humanism in medical training approached our residency program leadership with a curricular plan for EMRR. The proposal was to begin reflection rounds with a volunteer group of residents who would take part in monthly, hour-long sessions. Two faculty members (both EM attending physicians, one with additional training in palliative care) would facilitate the sessions. The expressed aims were to provide residents with a confidential environment to discuss difficult ethical and interpersonal encounters and to reflect on the unique challenges in medical training and in the high-stress, high-stakes field of EM.

During the inaugural year (2010-2011), nine residents (five females, four males; three each from postgraduate year 1-3) participated in the sessions. They were given asynchronous learning credit for their participation. At the beginning of every session, the faculty facilitators would ask if there were any particular cases that participants wished to discuss. A resident would share a recent case; then other residents and faculty would reflect on it, often building on it and adding their own experiences. Another case or two would be discussed in the same manner during the hour. Although there were no predetermined topics, a diverse range of topics were brought up over the course of the year, including death and dying, ethical dilemmas, disclosure of mistakes, physical and emotional wellness, and spirituality.
Ongoing verbal feedback from participants was solicited, culminating with a written, self-administered, anonymous survey that was done online through SurveyMonkey (Palo Alto CA, version 2011). The study was determined to be exempt by our Institutional Review Board and contained four questions. The first three questions were close-ended with a 1-5 Likert scale; the fourth question contained a free-text response (Appendix).

In the survey, all nine strongly agreed (5 on the $1-5$ Likert scale) that EMRR provided an important forum for residents to discuss difficult issues in a safe environment. All respondents strongly agreed that EMRR contributed to improving their own sense of well-being, and all strongly recommended EMRR for other EM residencies. Free-text comments noted the importance of EMRR as a means to discuss experiences of high emotional impact and feelings of isolation during training, as well as the importance of reflection and the impact of EMRR on developing emotional resilience and generating a sense of community among peers (Table 1).

\section{DISCUSSION}

Residency training is filled with challenging experiences, and there is a wealth of research on the rate of depression among residents and the association between depression, burnout, and lack of professionalism. Yet there has been a void in addressing wellness culture and finding concrete solutions to promote wellness during this period of medical training ${ }^{4}$; in fact, interventions have tended to focus on work-hour reform as the panacea for wellness. ${ }^{5}$ Reflective practice helps physicians-in-training identify with what they find meaningful in their work and has been shown to promote humanistic orientation. ${ }^{6}$ Indeed, it is an integral part of lifelong learning for professionals to analyze and learn from experiences. ${ }^{7}$ Yet residency has

Table 1. Free-text comments from the Emergency Medicine Reflection Rounds (EMRR) Survey

"We see a lot of tragedies in a high-stress environment. EMRR is a rare opportunity to process the gravity of what we do."

"Often, we feel like we're all alone. It's reassuring to know that other residents have similar experiences."

"It's an amazingly supportive group with a true sense of community."

"Learning to reflect on my reactions to my experiences, fears, and emotions has helped me become a better doctor."

"EMRR has helped me improve my interpersonal skills and psychological resilience." 
traditionally provided little opportunity for reflection on the challenges inherent in medical training. ${ }^{4,8}$

Implementation of the small-group reflection rounds at our residency has provided an opportunity for reflective practice and cooperative learning. In enabling a safe space to discuss challenging issues, it helps penetrate the culture of "silent bravado" of training. EMRR has also been useful in establishing a community of peers who are able to provide each other with mutual support. Moreover, this curricular intervention addresses three of the American College of Graduate Medical Education (ACGME) Core Competencies of interpersonal and communication skills, professionalism, and systems-based practice. ${ }^{9}$ It also addresses five of the Royal College of Physicians and Surgeons of Canada's CanMeds core roles of being a professional, communicator, collaborator, manager, and health advocate. ${ }^{10}$ By modeling professional characteristics such as humanism and reinforcing physicians' accountability to patients, EMRR helps overcome the "hidden curriculum" of graduate medical education. ${ }^{4}$

Based on the positive feedback as seen from the survey of the inaugural group of participants, EMRR has been expanded to our entire 60-member residency in the 2011-2012 year. It remains to be seen as to how EMRR will be perceived by residents who are required to take part in reflection compared to those who volunteered to take part; additional studies involving validated scales of burnout can also be of use in assessing the impact of the EMRR intervention. In the meantime, our pilot study demonstrates that opt-in small-group reflection rounds can be useful to augment an EM residency's wellness curriculum. It is a low-cost, logistically simple, and potentially highimpact intervention that may be of interest to other EM residencies around the world.

\section{SUMMARY}

Wellness in residency is an underemphasized yet critical topic, with few curricular interventions grounded in residents' day-to-day sources of ethical and emotional conflict. Implementation of opt-in small-group reflection rounds in an EM residency has been well received by the first group of participants. This curricular intervention promotes reflective practice and fosters cooperative learning around the communication, professional, and ethical challenges inherent in EM practice. Our EMRR model may be useful to other EM residencies looking to supplement their wellness curriculum.

Acknowledgements: We would like to acknowledge the resident leaders who made this curricular innovation possible: Drs. Lisa Arvold, Bernard Chang, Liza Gonen, Laura Janneck, Maggie Samuels-Kalow, Alex Sheng, and Jonathan Slutzman. We also thank Dr. Emily Senecal and Reverend Angelika Zollfrank for their assistance with small groups and Dr. Toby Nagurney for his help with critical analysis of the manuscript. Finally, we thank all the residents in our program for taking part in the EMRR.

Competing interests: None declared.

\section{REFERENCES}

1. Collier VU, McCue JD, Markus A, et al. Stress in medical residency: status quo after a decade of reform. Ann Intern Med 2002;136:384-90.

2. Givens JL, Tijia J. Depressed medical students' use of mental health services and barriers to use. Acad Med 2002;77:918-21, doi:10.1097/00001888-200209000-00024.

3. Pololi L, Frankel RM, Clay M, et al. One year's experience with a program to facilitate personal and professional development in medical students using reflection groups. Educ Health (Abingdon) 2001;14:36-49, doi:10.1080/ 13576280010015074.

4. Wen LS, Greysen SR. Keszthelyi D, et al. Social accountability in health professionals' training. Lancet 2011;378:e123, doi:10.1016/S0140-6736(10)62314-8.

5. Eckleberry-Hunt J, Van Dyke A, Lick D, et al. Changing the conversation from burnout to wellness: physician well-being in residency training programs. 7 Grad Med Educ 2009;1:22530, doi:10.4300/JGME-D-09-00026.1.

6. Branch WT Jr. The road to professionalism: reflective practice and reflective learning. Pat Educ Couns 2010;80:32732, doi:10.1016/j.pec.2010.04.022.

7. Schon DA. The reflective practitioner: how professionals think in action. New York: Basic Books; 1984.

8. Lefebvre DC. Perspective: Resident physician wellness: a new hope. Acad Med 2012. [Epub ahead of print]

9. American College of Graduate Medical Education. Core Competencies. Available at: http://www.acgme.org/acwebsite/ RRC_280/280_corecomp.asp (accessed April 3, 2012).

10. Royal College of Physicians and Surgeons of Canada. The CanMeds Physician Competency Framework. Available at: http://rcpsc.medical.org/canmeds/index.php (accessed May 2, 2012).

\section{APPENDIX: SURVEY QUESTIONNAIRE}

1. Please rank on a scale of 1-5: 1 being not at all; 3 being neutral; 5 being very much. How much does 
EMRR provide an important forum to discuss difficult issues in a safe environment?

2. Please rank on a scale of $1-5: 1$ being not at all; 3 being neutral; 5 being very much. How much does EMRR contribute to improving your own wellbeing?
3. Please rank on a scale of 1-5: 1 being not at all; 3 being neutral; 5 being very much. How much do you recommend EMRR to other EM residencies?

4. Please tell us about your experience as a participant in EMRR this year. In what way was it helpful to you? What suggestions do you have for improvement? 